\title{
National power measurement (case study: Oceania, Europa and North America)
}

\author{
Samira Motaghi ${ }^{1 *}$, Afshin Mottaghi ${ }^{2}$, Dmitry Pletnev ${ }^{3}$, Ekaterina Nikolaeva ${ }^{3}$, and Iuner \\ Kapkaev $^{3}$ \\ ${ }^{1}$ Payame Noor University, Minn City,Artesh Blvd, Tehran,19395-4697,Iran \\ ${ }^{2}$ Kharazmi University, 43, South Mofatteh Ave, Tehran, 15719-14911, Iran \\ ${ }^{3}$ Chelyabinsk State University, Br. Kashirinykh srt. 129, 454001, Chelyabinsk, Russia
}

\begin{abstract}
There is co-relation between national endowment and acceding to the health industry. The national power of each country reflects the level of influence at different levels of political, economic, and so on in order to advance a country's major goals. National power is not a mere abstraction, but the national power of a country is the result of a set of variables that all lead to the formation of a nation's national power. This article focuses on the national strength of the Western European Union (EU) countries of the United States, Canada, Mexico, Australia and New Zealand. As the national power of states determines the extent of their interactions and levels, it is necessary to investigate and measure this issue. In this paper, using the descriptive-analytical and mathematical methods of SAV and TOPSIS and finally averaging these two methods to measure the factors affecting the national power of countries based on the nine components of national power (political, economic, social, cultural, Educational, transboundary, space, territorial and military science).The results show that the United States, Canada, Germany, France, Australia, Luxembourg, Sweden, and Denmark ranks first.
\end{abstract}

\section{Introduction}

Considering the importance of having power in the regional and global arena today, it is important for national powers to regulate relations between countries based on their level of power. Today, the power of the Western Structural States is very important because measuring their strength can determine the type of regional and trans-regional interactions and interactions they have with each other, as well as with other countries. In the meantime, to identify the factors affecting national power, examine the relationship between countries. It can be argued that power relies on and derives from a variety of factors and resources. These are economic factors, personal and personality factors, scientific and cultural factors, social factors, and so on. In fact, the most important source of power is the feeling of inadequacy of others, in order to achieve this feeling of need for access to the various factors that are manifested as negative and positive factors in national power. There are various theories regarding the sources of power in general. Some factors are tangible and

*Corresponding author: samira.motaghi@gmail.com 
some rely on subjective and non-subjective factors while others point to both factors. The sources of power have been cited by various individuals, briefly referring to: personality, property, wealth, organization, law, military and military force, science, faith, piety and influence, communication and Media, environment and geography, physical attributes, authority, social and spatial position, leadership and management quality, unions, history, quantity and quality of population, economic quality and most importantly needless feeling. Given the role that national power plays in international interactions in the global arena, this study seeks to answer the question of the factors affecting the national power of Western structural countries including (EU countries), America, Mexico, Canada, New Zealand, and Australia and what are they? In addition, how much does each one weigh?

In relation to the functions of national power, scholars have paid much attention to the issue of national power and have examined this issue from a variety of perspectives. For this reason, measuring and measuring national power, and designing a comprehensive model and model for assessing the national power of countries, is one of the most important concerns of power experts. Many scholars have studied power, some of which have studied quantitative variables such as GDP, military power, population, size, etc., and others have studied mathematical models in addition to examining these variables. Used to determine the type of relationship and combination between variables. It is clear that the purpose of creating and developing a comprehensive model without knowing the work and criticism of others is not achievable. Therefore, in this section we examine the foundations and sources of national power from the point of view of experts To this end, we examined the sources and components of power from the perspective of 62 experts in the period 1939-2016. It can be noted that many of these views have many points in common and share many variables including geographical, economic, political, cultural, social factors.

\section{Research Methods}

This is a descriptive-analytical study. Firstly, using library studies and articles to define and explain the components that affect national power. Data collection tools include library studies, websites, strategic research center outputs, Persian and English articles, UN and subordinate agencies, catch-all and platforms. We then looked at variables associated with screening specialists and examined a number of variables that could be measured and measured. Then, the SAV and TOPSIS method were used to measure the national power of the countries, and then the mean scores obtained by both methods were used to increase the accuracy of the work. In the SAO method, after determining the significance coefficients of the indices based on the decision maker's views or using weighting methods such as the Shannon entropy, the special vector and the least squares method we obtain the coefficients of importance of each option and most of them We consider it the optimal option. That is, if the vector $\mathrm{W}$ (importance index weight) is assumed to be the most appropriate option $(\mathrm{A} *)$ then $\mathrm{A}$ is obtained.

In TOPSIS, there are also a number of decision-making options and a number of criteria for decision-making that need to be ranked according to the criteria, or assigned to each one a performance score. The general philosophy of the TOPSIS method is that, using the available options, two hypothetical options are defined. One of these options is a set of the best values observed in the decision matrix. We call this option ideally positive (best possible). In addition, another hypothetical option is defined that includes the worst possible cases. This is the ideal negative option. Criteria can be positive or negative in nature, and the unit of measurement may also be different. The criterion for calculating scores in the TOPSIS method is that the options are as close to the ideal positive option as possible and away from the negative ideal option. On this basis a score is calculated for each option and the options are ranked according to these scores. 


\section{Research findings}

What is at stake in this research is the ranking of the Western Structural States on the basis of the nine components of national power. In fact, in this study we examine and compare the structural states of the West with each other, which then briefly discusses the variables considered in this study.

\subsection{Ranking the Power of Countries by Social Factor}

Social power is based on the trust and confidence of society in its institutions, forces and individuals, and it seems from the same point of view that the structure of trust and obedience between political (government) and social (nation) fragility is fragile. Social refers to institutions and forces that lack the power and means of material pressure but which have spiritual influence in society. Compared to political power, social power actually benefits from "soft power". One of the key elements of soft power is "the ability to attract the consent and consent of others." According to Joseph Nye, it is the soft power that is capable of shaping the will and preferences of others that attracts others [1]. On the other hand, it can be stated that social power seeks control and access to important resources (rewards, money, social gratitude, etc.) [2]. In fact, it can be argued that assessing social power is crucial to identifying the extent to which community leaders are empowered [3]. Some scholars view social power in relation to social orientation, situational goals, and personal communication $[4,5]$. Finally, it can be acknowledged that high social power for nations and nations can provide relative independence from others, while having low social power means being dependent on one nation and country and losing decision-making opportunities at levels. Is high [6]. According to the theories of the experts in this field, the following variables have been used to measure the national power of the Western European Union (EU), USA, Canada, Mexico, Australia, New Zealand:

We will continue to rank the Western Structural Countries of 33 countries (EU), USA, Canada, Mexico, Australia and New Zealand. As we can see in fig. 1, Italy, the United States, Luxembourg rank first to third. And Estonia, Latvia, Romania and Bulgaria have the least weight. Given that social power is composed of many influential variables, it can be seen from the results of the data that Italy has been able to reduce sexual inequality, increase per capita health expenditure, increase per capita income over the past decade. Tourism should be given a higher weight than other Western Structural countries.

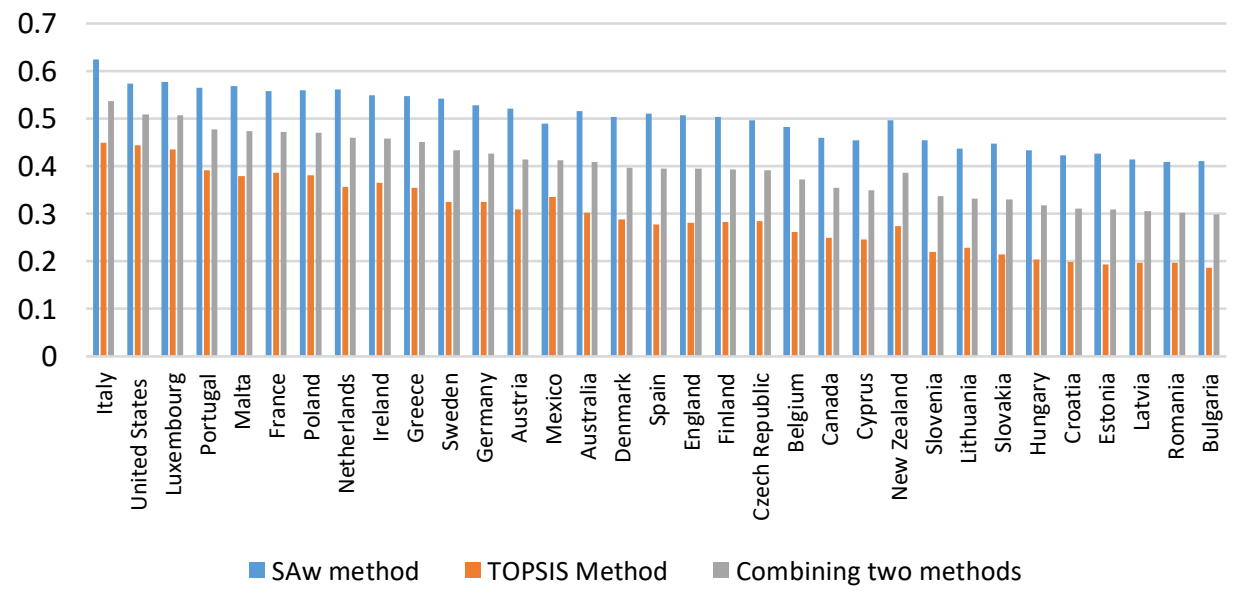

Fig.1. Ranking countries by social variable 


\subsection{Ranking countries' strengths based on technology scientific factor}

Science and knowledge are a systematic set of data that is located in a specific context whose ultimate goal is to perceive and develop technology as the medium and instrument of human domination over the environment. In fact, science is a tool for discovering the truth and the product of scientific knowledge. Science and research, in addition to discovering natural secrets, has the potential to eliminate social and political unrest and minimize social inequality [7].Therefore, it can be stated that science and technology, given the role they play, can enjoy immense power in achieving states and nations in pursuit of their goals and the preservation of their interests. Concerning the power of science and technology, Fukuyama states: "From the perspective of Hegelian Marxist understanding, the root of history ultimately lies in science and technology. Science is accumulative, and we periodically forget about historical discoveries. This is the builder of the economic world, because technology is a horizon of economic production possibilities and ensures that there is a difference between the era of the steam engine with plowing, and the era of transistors and computers with the era of steel and coal. Scientific development enables the unprecedented increase in productivity that springs from modern capitalism and the liberation of technology and ideas in modern market economies" [8]. With the advent of modern science and technology in the world today, progress is rapidly being made by many scholars to this type of power. Due to the change of power from hard to soft, one of the most important areas of soft power is scientific and technological power. Therefore, examining this issue and its role in national power is important from a geopolitical point of view. From the data obtained, it can be seen that the United States has gained greater strength among the Western Structural Countries due to its high technology and high added value in commodity production. It should also be noted that due to its vast facilities, many of the Third World elites have been attracted to it and have been able to contribute significantly to the enhancement of its scientific power through the dissemination of articles and the use of new technologies (fig. 2).

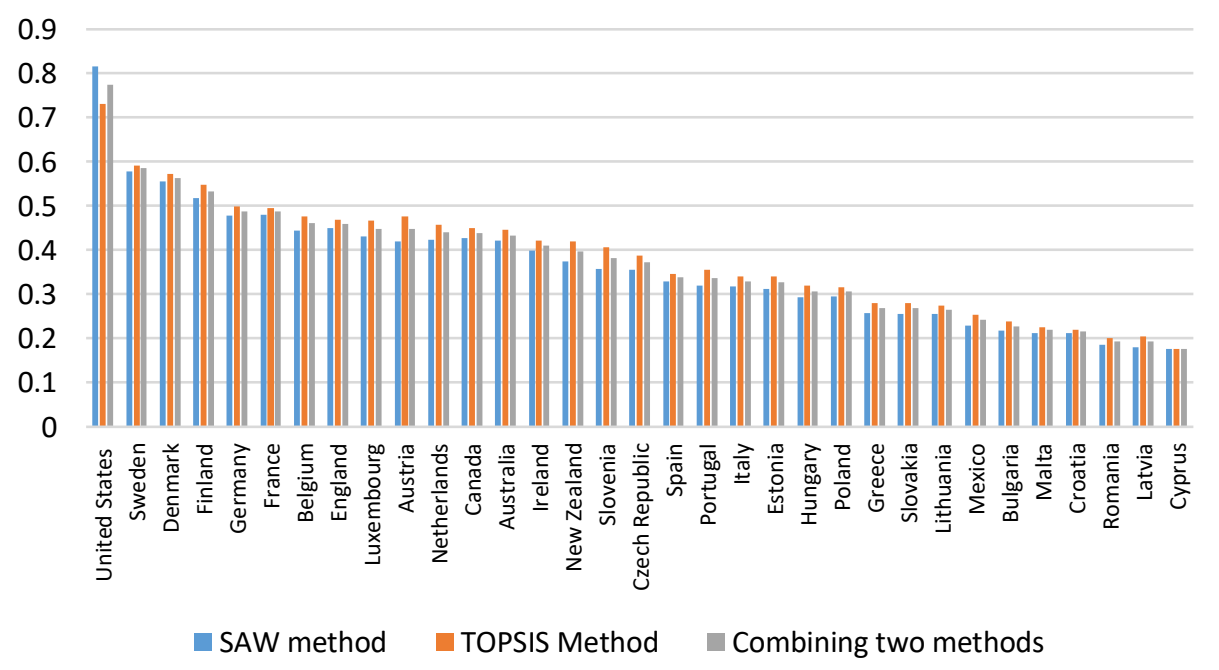

Fig. 2. Ranking countries by scientific power of technology

\subsection{Ranking countries' strengths by economic factor}

Historically, key aspects of power, whether political, ideological, military or economic, are 
concentrated within the state. The nation-state is a major player in governance in the domestic arena. Given the era of globalization and economic integration, it can be said that the economy can play a significant role in the field of national power. Today, the economy at the local level is interacting with the international and global economy. This includes government and non-state actors. Therefore, it can be argued that economic power is paramount in the development of global governance in the 21 st century. Economic power actually represents purchasing power and market power. According to the traditional definition of power in this type of power, three uses can be considered: power is an advantage that gives the actor the ability to play; purchasing power can include goods and services and therefore represent wealth and the ultimate market power that represents the competitive nature of the players on a micro and macro scale. For example, the threat of access to global and international markets, increased trade barriers, austerity in domestic and foreign investment, etc. is one example of countries exercising economic power over others. The power in this context is a reflection of the degree of economic dependence (integration) between countries or groups of countries. Therefore, any measure of economic power can alter the ability to impose economic sanctions and related threats. Another element of economic power lies in the desire of countries to be represented in international negotiations and cooperation on joint agreements. Thus, in global negotiations, economic power can influence the interactions of countries based on international law and the sovereignty regime. The agreement can be found through a set of common rules and strategies in domestic and foreign investment. Economic power in this case can be accompanied by coercion that increases the responsiveness of inter-group coalitions. Another dimension of economic power is the epistemological orientation which, in fact, evokes the understanding of soft power to influence other countries. The term legitimacy is generally used to further influence this term. Thus, competitors are persuaded to safeguard their interests without violating international law. In this context, it can be seen that the United States of America is in the first place with the highest economic position compared to other countries. This indicates the high return on investment, cross-border investment, export, capital mobility, economic freedom, and so on. Undoubtedly, a country with a higher weight in these variables could be in the grip of the regional and even global economic power pyramid (fig. 3).

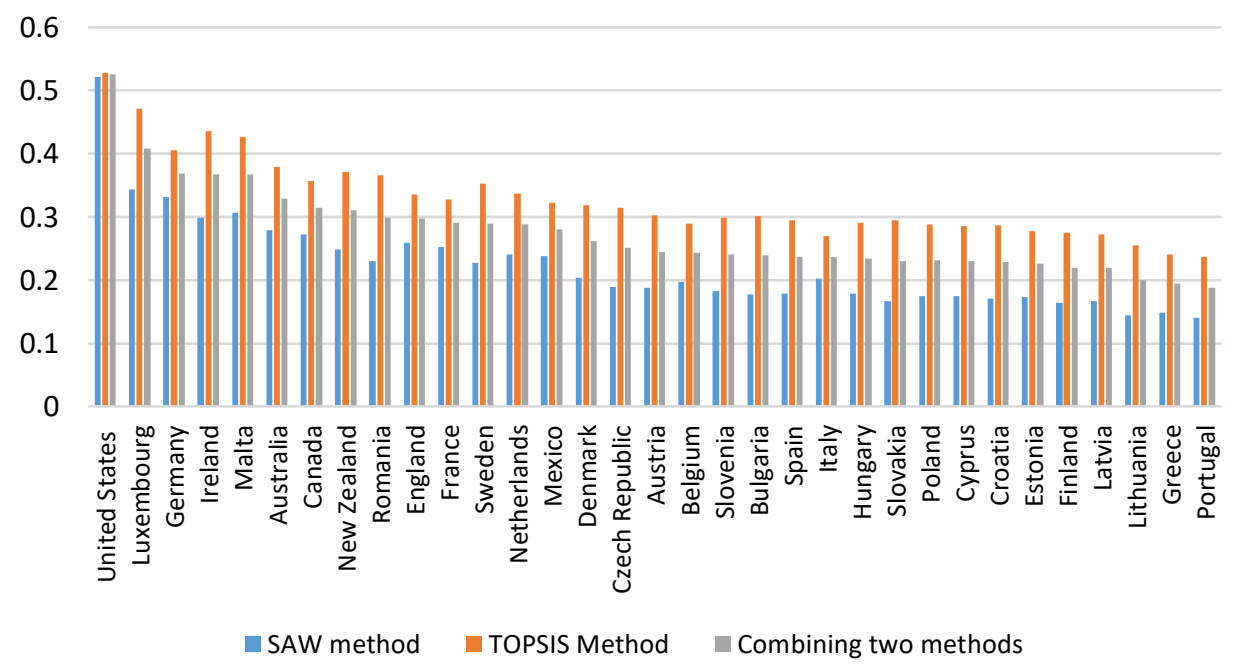

Fig.3 Countries ranked by economic variables 


\subsection{Ranking countries' strengths based on territorial factor}

In the geopolitical definition, three elements of power, politics and geography play a role. Geographical spaces, meanwhile, contain values that are manifested in the behavior and behavior of humans as a group or individually. As geopolitical competition is about space, attention to geographical and territorial spaces is of great importance [9]. Accordingly, some of the factors and sources of national power lie in the geography and territory of each country, and most importantly, geographical features often play a fundamental role in shaping other elements of economic, political, and military power. Therefore, geography is of particular importance in analyzing the national power of a country. The environmental framework of national or global arenas can affect national power. The relative advantage that one country gains over another through different distribution of resources, economic development, and other forms of wealth can complement this effect [10]. All the scholars who have studied the sources of national power have mentioned geography and territorial factors as one of the main pillars of national power. Even some in the past have defined geography as the main factor of national power. Goldstein, for example, emphasizes the geography and geopolitical position of a country among the sources and sources of power and states that the most important three considerations of a country's real status are: position, position, and position [11]. In general, national power in some circumstances derives from geopolitical factors. This is quite obvious in the field of strategy, and so is in the case of international economics and politics. Therefore, in order to understand the role of power in the world, one must first get acquainted with the factors of geographical policy. In this component, as can be seen, the United States and Canada have a higher weight than other countries, due to the high importance of the extent of territorial power, and because of the lesser extent, European countries often derive from mineral, metallic and mineral resources. In addition, they also have less food, and the breadth of the issue has made them less weighty (fig. 4).

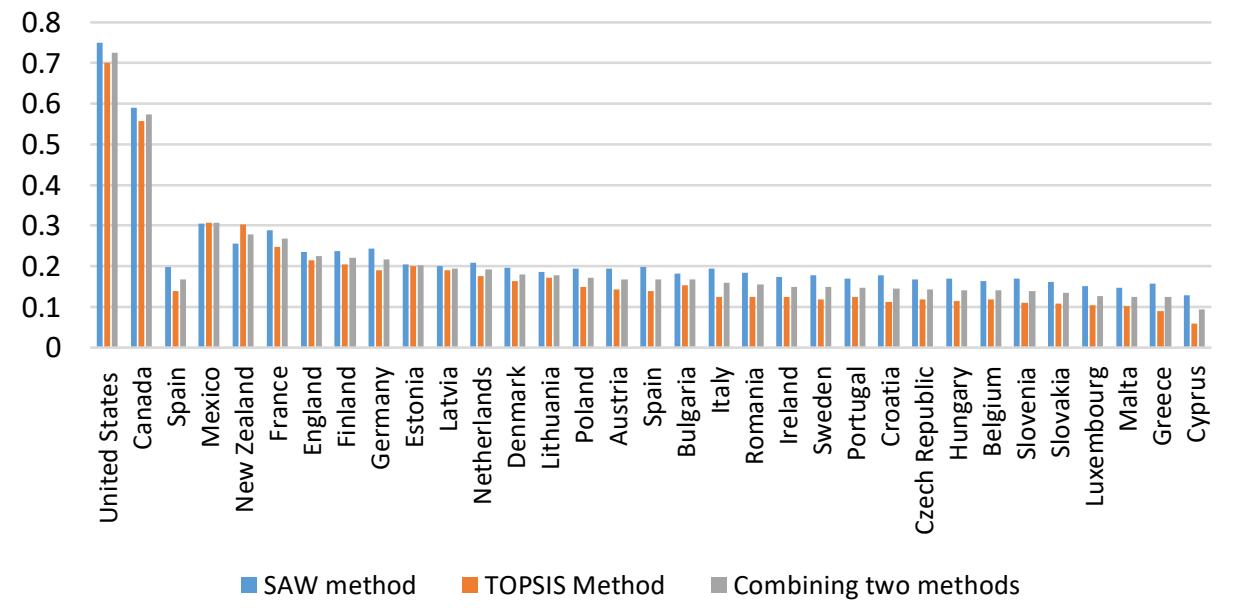

Fig. 4. Ranking countries by territorial variable

\subsection{Ranking countries' power based on political factor}

Although power is not limited to political power and extends to economic, social, cultural, and so on, political power is the most obvious manifestation of power. With the formation of human society and the move towards the formation of political society, political power is 
necessarily produced. The social nature of man is brought together by his fellowmen through civility or rational choice. As human relationships evolve and become organic in society, human rights clashes with one another. It is at this stage that there is a need for a jurisprudential power that regulates the relations of individuals, and that political power inevitably emerges within the framework of government, leading to the division of society into rulers and rulers. In other words, political power is the product of the emergence of political society. A political society that, with the evolution of social organization and the establishment of normative legal order, simultaneously assumes a distinctive externality with a sense of belonging to it, and with the three characteristics of being universal, having the necessary character and power to act from it. Other communities are diagnosed. Therefore, the political community can be considered as a combination of political power and the aim of such power is to exercise a special form of power such as governance and political affairs. In defining political power, Foucault discusses the power of the model of sovereignty. Since sovereignty is expressed in relation to geographic space and nation, it can be stated that political power can be one of the factors influencing national power. Because the power of political leaders and rulers in terms of strategy, strategy, civil liberties and human rights itself can influence their power in the national and international arena and ultimately their influence on decisions and so on. In the political context of the West, the structural states of the West are often close to each other. This is due to the progress made in the field of democracy, quality control of corruption, quality of rule of law, quality of regulation, political freedom, and civil liberty and so on. In this context Sweden, Denmark and New Zealand enjoy better conditions than other countries. It shows the importance of democracy and the people of society for the governments of these countries (fig. 5).

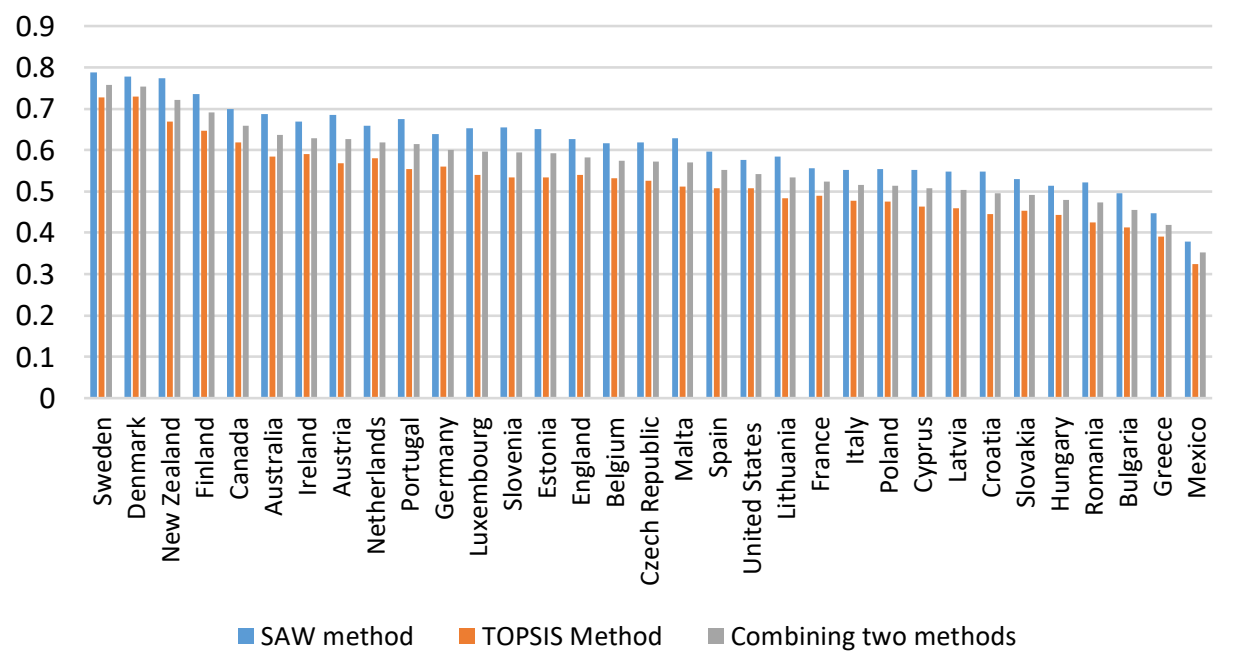

Fig. 5. Ranking countries by political variable

\subsection{Ranking countries' strengths based on cultural factors}

In social life, the phenomenon of culture and politics are often intertwined, often indicating the connection between culture and politics and the hidden connections between these two areas. Now the question is why culture is involved in national power? In the first place, it can be acknowledged that culture reflects the way people study, the speeches of politicians, the extent to which the nation is aware of events and so on. In fact, it can be stated that 
culture at this stage is inextricably linked to national power. On the other hand, one can analyze that power relations are flowing in the social, economic and administrative fields. And in fact it is structurally represented by the preservative force of government and politics in the social sphere. For example, Huntington's theory of clash of civilizations can be mentioned. He argues that cultural faults in the future will pave the way for war and crisis. In his book, Patrick Chanel states that politics and power are influenced by culture today, thus analyzing Western political systems based on cultural development assumptions. The intertwining of culture and power leads to the discovery of hidden relationships and political dimensions of culture [12]. So it can be said that culture is directly linked to political and power factors. For example, we can say that the influence of culture and the mood of nations and nations, as well as how national culture influences foreign policy and international behavior, but also on the way war and defense are affected. This means that countries have their own culture of fighting. Therefore, paying attention to this component in national power is very important. Finally, it can be stated that each nation has its own culture, tradition, socio-mental infrastructure, and political arrangements that form the cultural and communication foundation of the nation-state [13]. Therefore, awareness of the type of culture measuring the cultural characteristics of the nation-state can have a positive impact on the process of regional and international interaction. In this context, the high importance of literacy, education costs, gender difference, Legatum happiness index, etc. Has made countries like New Zealand, Denmark and Finland weightier than other countries. The importance of this component is that the high cultural power is the increase in the soft power of states at the regional and global level, which can move through persuasion and soft power to persuade and achieve their national goals and interests, and a country with power The higher the softness, the greater the cultural component (fig. 6).

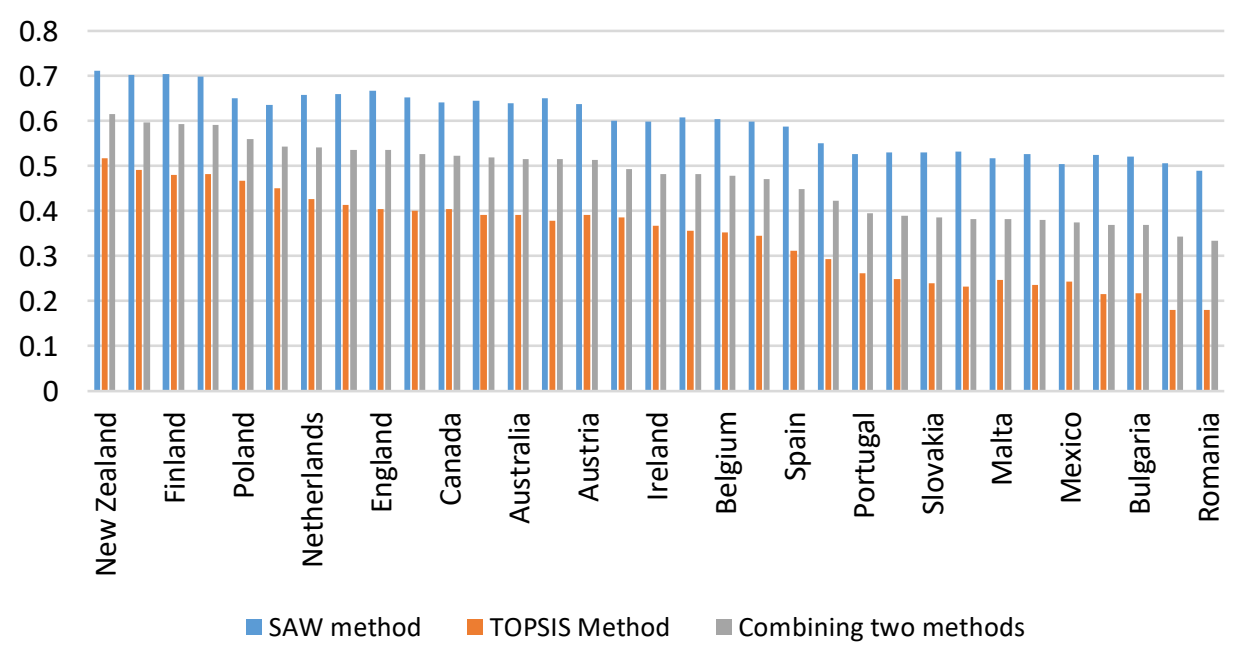

Fig 6. Ranking countries by cultural variable

\subsection{Ranking countries' power by military factor}

Although national power is a central theme in the art and knowledge of strategy, military power remains one of the important dimensions of national power, given the developments that have taken place in recent decades and its role has been somewhat diminished. Military power is of great importance because it is more tangible, practical and manifest than other 
dimensions of power. That is, it is still a key factor in determining the national security of a country, especially foreign security, against foreign threats. Military Elements in National Power including Military Objectives, Military Doctrines, Military Strategies and Policies (Defense, Non-Defense), Forces and Their Bags, Training, Command, Military Technologies, Weapons and Equipment, Military Organization, Military Budget, Military bases, mobility, logistics, etc. Some scholars argue that military power lies in lower defense spending and direct investment [14]. Given the deterrent role played by Tohwa's military power, it is very important after this national power. In this context, the United States is more heavily weighted than other Western structural countries, reflecting the superior power of the United States at regional and global level. The high levels of variables such as arms exports, the number of armed forces, aircraft carriers, and the number of nuclear weapons represent the United States' superior military strength (fig. 7).

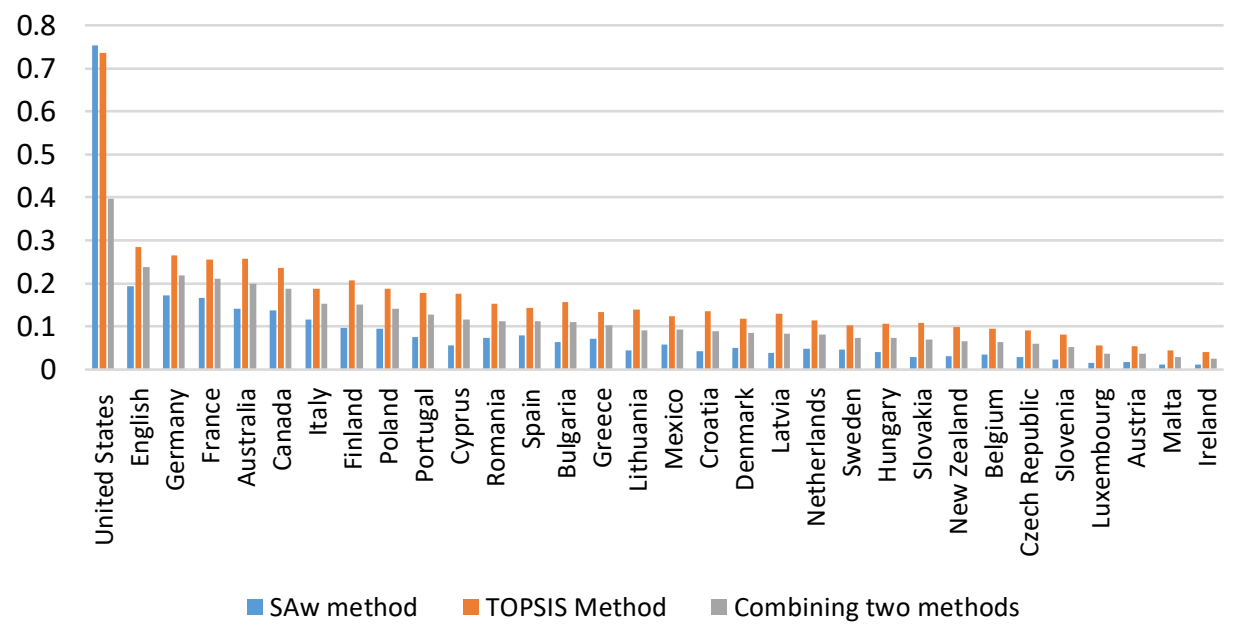

Fig. 7. Ranking countries by military variable

\subsection{Ranking countries' power based on transboundary and spatial factors}

Today, with the expansion of globalization, the world today has become a small village characterized by the compression of time and space. Today, countries have to communicate and expand their engagement at regional, trans-regional, global and international levels to maintain their interests and achieve their goals. Today we are seeing countries with lower levels of transnational interactions becoming more involved in isolation and increasing entropy, which makes it difficult for nations to govern. In fact, it can be argued that this point seems to be in favor of transnational foreign policy, which is based on commitment to and participation in changes that drive governments out of classical isolation and foreign policy. Expanding transboundary interactions can be synonymous with refusing military presence in different parts of the world so that they can have their influence in secret in different areas, and on the other hand, it can be openly and on military base be raised. For example, the question of the transboundary presence of American forces in various regions of the world can be mentioned. Given the importance of trans-frontier facilities and the role they can play in national power, it is essential to identify the trans-frontier facilities of other countries. The rise of transboundary power reflects the broader relations and interactions of a country at the regional and global level, and the greater the interactions, the more economically, politically, culturally and militarily a country can have greater power and its policies in line with its goals. In addition, implement national interests. The United States 
has a much higher weight in this component than any other Western structured country (fig. 8).

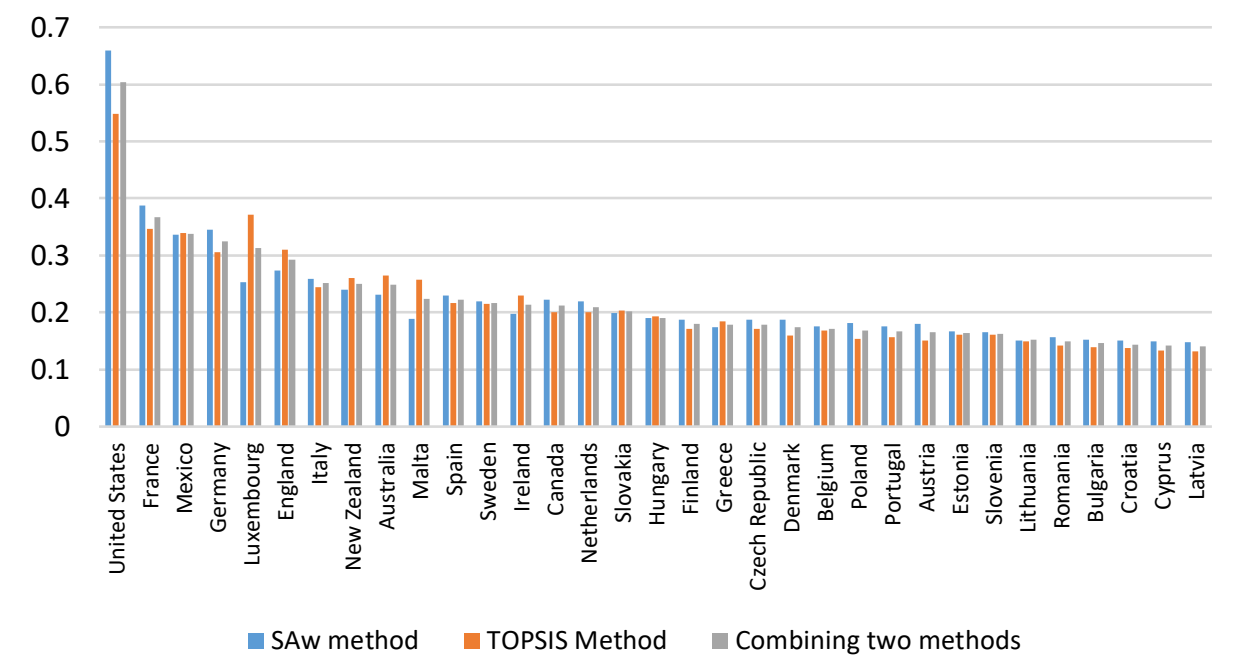

Fig. 8. Ranking of countries by transboundary variable

Power in the field of space technology, like everything else in the world, has a simple definition. Countries that have more advanced technologies and make more money in the space sector fall into the category of space superpowers. Countries such as Russia and the US are still recognized as the traditional superpowers of space in the world. The summarizing results of calculation of national power is presented on fig. 9

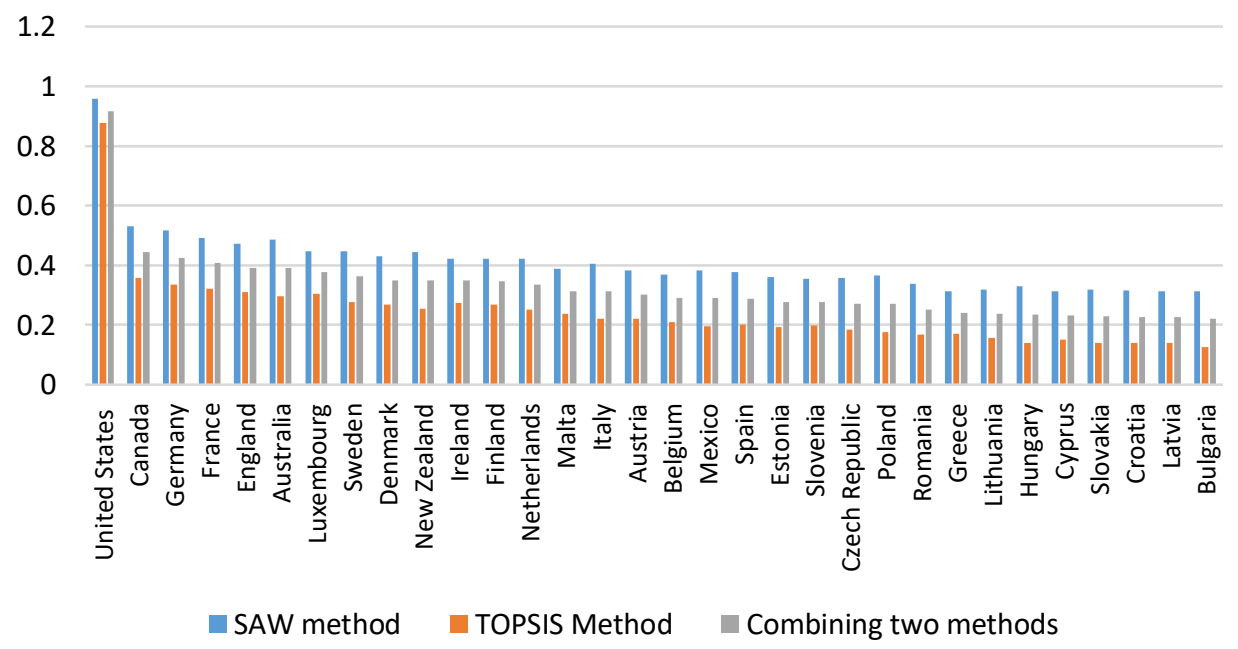

Fig. 9. Ranking of countries by national power

\section{Conclusion}

National power as a set of material and spiritual capacities composed of various fixed and variable elements that are in the territory of a geopolitical unit called the state or state. Creating a framework for comparing and ranking countries in terms of national power has 
always been one of the concerns of experts in the fields of political science, political geography, and international relations. The expression of national power in the number and ranking of countries in terms of national power in the international system is of particular importance because the awareness of countries about their national power and that of other countries helps them to adopt appropriate strategies to pursue national goals at the global level. Since the Western Structural countries, which consisted of 33 countries and today have a significant role in foreign, economic, social, cultural, transboundary and other fields in regional and global developments, it was necessary to examine and rank these Countries to pay. According to studies by various research centers, by 2030, the United States will continue to have undisputed military power. On the other hand, it can be acknowledged that the EU could emerge as a superpower in the near future if the European Union could pass separatist movements among its members. The region's population, economy, and area equate with the United States, and it seems that the region is trying to challenge American power as a superpower. Since the early 1990s, the European Union, by formulating its own defense policy known as the CSDP, has been trying to pull itself out of NATO's dominance, which could in the future alter the balance of power in Western structures. As for France, France once ruled many parts of the world and still maintains military bases in areas such as the Horn of Africa and the Persian Gulf. France has the most nuclear weapons after the US and Russia, and in addition, it continues to exert its influence on the countries that were once colonies of France through its French language and education system, thereby increasing its power, in the future.

\section{References}

1. N. Vaezshahrestani, Payam Baharestan, 1(40), (2009)

2. A. Scholl, S. Kai, British Journal of Social Psychology, 57(1), 112-129 (2017)

3. C.Y. Chiu, The Leadership Quarterly, 28 (2), 334-348 (2016)

4. A.D. Galinsky, J.C. Magee, Social Psychological and Personality Science, 5, 627-635 (2014) https://doi.org/10.1177/1948550613519685

5. S. Huber, B. Johannes, Journal of Numerical Cognition, 2363-8761 (2017)

6. A. Scholl, K. Sassenberg, Journal of Experimental Social Psychology, 53, 51-61 (2014) https://doi.org/10.1016/j.jesp.2014.02.005.

7. J. Mousavi Zare, S. Zarqani, H. Azami, Journal of Political Geography, 1(3), (2016)

8. M. Hedayati, A. Ahmadvand, H. Hatami, Afaf Security Journal, 5(18), (2013)

9. A. Abdi, Geopolitical Quarterly, 20(3), (2015)

10. H. Kamran, Y.A. Gholami, K.H. Amini, Journal of Geographical Sciences Applied Research, 13(16), (2010)

11. J. Goldstein, International Relations (Longman, New York, 1999)

12. E. Wolf, Pathways of Power. Building Anthropology of the Modern World (Hans Schoenmakers, 2011)

13. A. Iriye, Power and Culture: The Japanese-American War, 1941-1945 (Harvard University Press, Cambridge, 2009)

14. D. Drezner, N. Hite-Rubin, Sustainable Security: Rethinking American National Security Strategy (Oxford University Press, 2016) 